\title{
STUDI KASUS PADA METODE DAN TAHAPAN PENGENALAN PERANCANGAN KAPAL PENANGKAP IKAN
}

\author{
Case Study on Design Method and Stages of Recognition Fishing Vessel \\ Oleh: \\ Herianto Suriadin'1, Angkasa Putra ${ }^{2}$ \\ ${ }^{1}$ Fakultas Perikanan dan Ilmu Kelautan, Universitas Muslim Indonesia \\ 2 Program Studi Teknologi Akuakultur, Politeknik Ahli Usaha Perikanan Jakarta \\ * Korespondensi: heriantosuriadin@gmail.com
}

\begin{abstract}
Ships are a means of transportation used by humans to carry cargo (goods or passengers) from one place to another in an area of water and are built in accordance with their respective interests. The purpose of this study was to determine the methods and stages of introduction of fishing vessel design. The usefulness is to add insight to be developed in the world of marine and fisheries. This research was conducted on June 27 to August 1, 2019 with a period of 36 days located in the Center for Fishing (BBPI) Semarang. The method used is primary and secondary data collection including direct observation at the research location and literature study as a complement to the data. In the fishing boat design method, the stages include: the comparative ship method, the statistical method, the iteration method, and the method of complex solution while the fishing boat design stage includes the design of the technical aspects, the estimated cost of building the ship, and the design of the financial aspects of the ship's operations.
\end{abstract}

Keywords: design methods, design stages, fishing vessels

\begin{abstract}
ABSTRAK
Kapal merupakan sarana perhubungan yang dipergunakan manusia untuk membawa muatan (barang atau penumpang) dari tempat satu menuju tempat yang lain di daerah perairan dan dibangun sesuai dengan kepentingannya masing-masing. Tujuan penelitian ini adalah untuk mengetahui metode dan tahapan pengenalan perancangan kapal penangkap ikan. Adapun kegunaannya yaitu sebagai penambah wawasan untuk dikembangkan dalam dunia kelautan dan perikanan. Penelitian ini telah dilaksanakan pada tanggal 27 Juni sampai 01 Agustus 2019 dengan jangka waktu 36 hari yang berlokasi di Balai Besar Penangkapan Ikan (BBPI) Semarang. Metode yang digunakan yaitu dengan pengambilan data primer dan sekunder meliputi observasi secara langsung di lokasi penelitian, serta studi literatur sebagai pelengkap data. Dalam metode perancangan kapal penangkap ikan, tahapannya antara lain: metode kapal pembanding, metode statistik, metode iterasi, dan method of complex solution sedangkan tahapan perancangan kapal penangkap ikan meliputi perancangan aspek teknis, estimasi biaya pembangunan kapal, serta perancangan aspek finansial operasional kapal.
\end{abstract}

Kata kunci: kapal penangkap ikan, metode perancangan, tahapan perancangan

\section{PENDAHULUAN}

Perikanan dan kelautan adalah salah satu potensi sumber daya alam yang dimiliki Indonesia untuk meningkatkan sektor ekonomi. Usaha dalam meningkatkan pertumbuhan ekonomi sektor kelautan dan perikanan adalah dengan meningkatkan kegiatan pemanfaatan sumber daya perikanan dan memproduksi komoditas ikan laut dengan operasi penangkapan ikan. Maka peranan dari kapal perikanan sangatlah penting dalam penangkapan ikan. Kapal merupakan saran 
perhubungan yang dipergunakan manusia untuk membawa muatan baik barang atau penumpang dari tempat satu menuju tempat yang lain di daerah perairan dan dibangun orang sesuai dengan bermacam-macam kepentingan kapal (Unus 2004).

Berdasarkan Surat Keputusan Menteri Kelautan dan Perikanan Nomor:19/PERMENKP/2014, BBPI merupakan Unit Pelaksana Teknis (UPT) di bawah Direktorat Jenderal Perikanan Tangkap (DJPT) yang mempunyai fungsi uji terap, penyebaran informasi pemanfaatan sumber daya ikan, pelayanan dan kerja sama teknis, pengujian dan sertifikasi, bimbingan teknis, dan pengelolaan sistem informasi di bidang penangkapan ikan. Uji terap teknologi pemanfaatan sumber daya ikan yang dilakukan salah satunya adalah uji terap teknologi kapal perikanan, khususnya kapal penangkap ikan. Kapal penangkap ikan adalah sarana apung penangkapan yang mempunyai geladak utama dan/atau bangunan atas/rumah geladak yang secara khusus dipergunakan untuk menangkap ikan, termasuk menampung dan mengangkut, menyimpan, mendinginkan atau mengawetkan (SNI 01-7277.2-2008).

Kapal penangkap ikan yang dominan digunakan oleh nelayan di pantai utara Jawa adalah kapal penangkap ikan dari bahan kayu. Oleh karena itu, dilakukan observasi mengenai kapal penangkap ikan dari bahan kayu. Kapal penangkap ikan yang menjadi objek adalah kapal milik BBPI yang terpajang di lingkungan BBPI. Tujuannya adalah untuk mengetahui metode dan tahapan perancangan kapal penangkap ikan.

\section{METODE}

Penelitian ini dilaksanakan di BBPI Semarang, Jawa Tengah (Gambar 1) selama 36 hari yaitu pada tanggal 27 Juni 2019 sampai dengan 01 Agustus 2019.

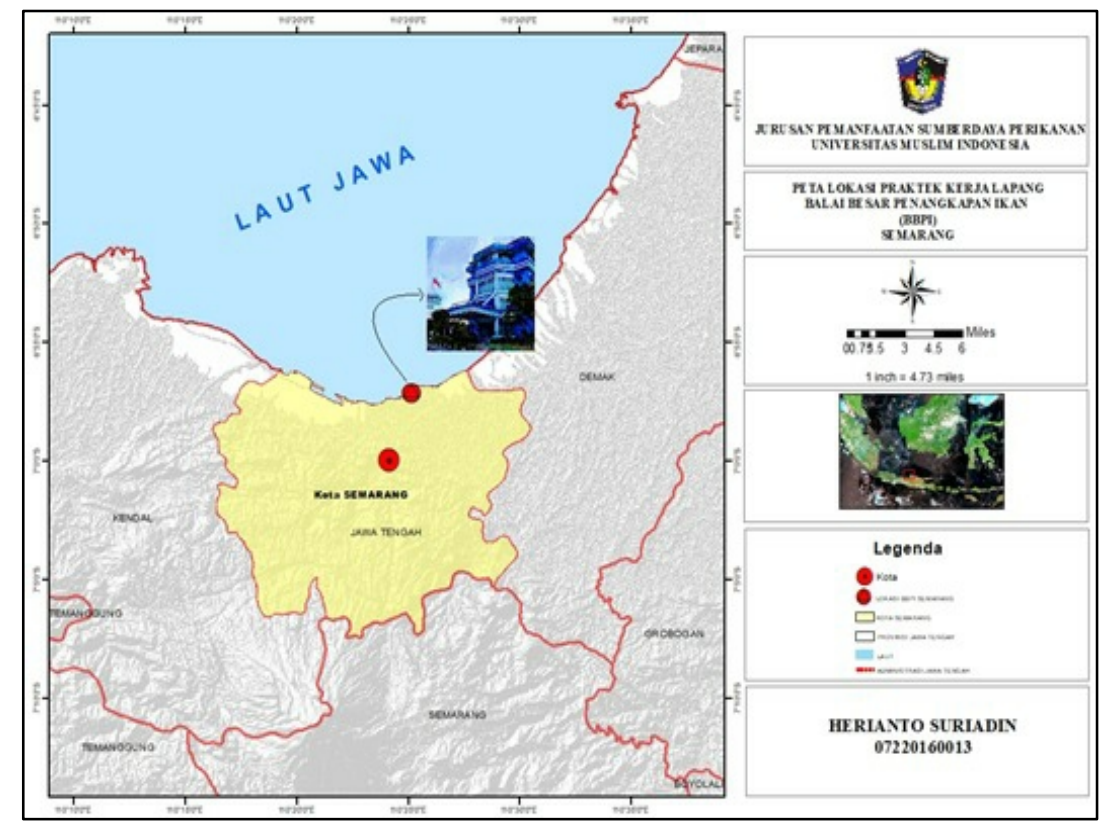

Gambar 1 Peta lokasi penelitian

Pengambilan data penelitian dilakukan dengan partisipasi aktif di BBPI Semarang. Bentuk partisipasi yang dimaksudkan adalah keikutsertaan atau keterlibatan seseorang (individu atau kelompok) dalam suatu kegiatan tertentu. Keikutsertaan atau keterlibatan yang dimaksud di sini bukanlah bersifat pasif tetapi secara aktif ditujukan oleh yang bersangkutan. Metode partisipasi aktif dilakukan dengan cara ikut serta dalam kegiatan di lingkungan BBPI Semarang dan secara aktif dibimbing oleh pembimbing lapang dari BBPI Semarang. Sehingga dapat mengetahui dan memahami secara langsung antara kesesuaian serta keterkaitan antara teori dengan fakta di lapangan. 
Adapun jenis data yang digunakan yaitu data primer dan sekunder. Data primer adalah sumber data penelitian yang diperoleh secara langsung dari sumber aslinya, salah satunya dengan observasi. Menurut Djaelani (2013), metode observasi dilakukan dengan cara mengamati perilaku, kejadian atau kegiatan orang atau sekelompok orang yang di teliti, kemudian mencatat hasil pengamatan tersebut untuk mengetahui apa yang sebenarnya terjadi. Dengan pengamatan peneliti dapat melihat kejadian sebagaimana subyek yang diamati mengalaminya, menangkap, merasakan fenomena sesuai pengertian subyek, dan obyek yang diteliti. Selain itu juga digunakan data sekunder berupa basis data yang kami terima dari BBPI Semarang maupun studi literatur. Berdasarkan dua jenis data tersebut dan metode yang diterapkan, digunakan untuk mengetahui metode dan tahapan perancangan kapal penangkap ikan.

\section{HASIL DAN PEMBAHASAN}

\section{Metode Perencanaan Rancangan Kapal Penangkap Ikan}

Menurut Palgunadi (2007) desain adalah suatu istilah yang lebih banyak digunakan untuk menunjukkan suatu rencana atau suatu proses perencanaan yang bersifat mikro (kecil, khusus, spesifik, sempit, khas, detail, rinci). Istilah dari rancangan, juga setara dengan desain, tetapi dalam penggunaan atau penerapannya, umumnya lebih banyak dipakai di bidang pakaian, fashion, pola, atau tekstil. Rancang bangun maknanya setara pula dengan desain, tetapi dalam penggunaan atau penerapannya, umumnya lebih banyak dipakai di bidang konstruksi, bangunan, pekerjaan teknik sispil, dan arsitektur.

Dalam perancangan kapal penangkap ikan yang perlu diketahui yaitu metode perencanaan yang akan digunakan. Menurut Ronald et al. (2014) secara umum metode perancangan kapal yaitu:

1) Metode Kapal Pembanding (Method of Comparison Ship)

Metode ini sering digunakan oleh pihak galangan kapal dalam merencanakan kapal baru. Dasar pemikiran metode ini adalah merencanakan kapal yang lebih baik dari kapal sebelumnya. Dalam perencanaan kapal dengan menggunakan metode ini, pengalaman perencana (designer) juga diperlukan. Walau pada dasarnya dalam merencanakan kapal baru, metode ini tidak digunakan, melainkan hanya untuk pengembangan tipe yang telah ada. Keuntungan metode ini adalah apabila perencanaan berhasil maka akan menambah pengalaman untuk perencanaan kapal selanjutnya, perencanaan cepat dan sederhana, serta resiko kegagalan sedikit karena bersifat untuk memperbaiki dari kapal yang sudah ada baik dari aspek teknis maupun ekonomis.

2) Metode Statistik (Method of Statistic)

Metode ini tidak tergantung langsung dari kapal pembanding. Adapun cara untuk mendapatkan data statistik, dilakukan dengan menganalisis beberapa kapal modern untuk mendapatkan ukuran utama, parameter bentuk, dan hasil-hasil percobaan. Metode ini digunakan untuk memecahkan perhitungan ukuran utama, perhitungan berat bagian konstruksi, perhitungan tenaga penggerak kapal, dan lainnya. Hal-hal yang perlu diperhatikan dalam penggunaan metode statistik adalah memperbaiki secara terus menerus semua statistik data-data kapal baru, sehingga memungkinkan memperkecil kesalahan-kesalahan perancangan.

\section{3) Metode Iterasi (Method of Trial and Error/lteration)}

Metode ini paling banyak digunakan dalam perencanaan kapal. Ukuran utama akhir didapat setelah diadakan beberapa kali ulangan perhitungan (trial and error). Metode statistik juga dapat dipakai dalam proses metode ini. Grafik yang menunjukkan proses metode ini disebut dengan desain spiral. Semua parameter sangat tergantung satu sama lain, oleh karena itu perubahan dari parameter akan memengaruhi yang lain dan semua parameter pada setiap putaran. Beberapa keuntungan metode ini yaitu: besar tenaga penggerak/mesin, kapasitas ruangan dan stabilitas harganya dapat ditentukan sejak awal, ulangan perencanaan tidak diperlukan, dan perjanjian dengan pihak pemesan dapat dilakukan dengan lebih cepat.

\section{4) Method of Complex Solution}

Metode ini terutama dipakai untuk kapal-kapal yang harganya relatif tinggi atau kapal yang rumit dan cocok juga untuk tipe baru. Metode ini jarang digunakan dalam perencanaan kapal kecuali 
dikombinasikan dengan metode perbandingan dan metode statistik. Dalam pelaksanaan metode ini, susah dilaksanakan dengan tangan karena akan membutuhkan waktu yang lama, sehingga harus menggunakan komputer. Ukuran utama didapat dengan perhitungan dari persamaan yang pasti. Ketelitian pekerjaan cukup pasti sehingga tidak diperlukan koreksi dalam pekerjaannya.

\section{Perencanaan Perancangan Kapal Penangkap Ikan}

Berdasarkan penyusunan basic design rancang bangun kapal perikanan oleh PT. Tulada Konsula (2005) diketahui bahwa tahapan perencanaan kapal sebagai berikut:

\section{1) Rancangan Awal (Preliminary Design)}

Rancangan ini merupakan langkah mempersiapkan dan mengevaluasi data kapal perikanan. Adapun data yang perlu disiapkan dalam rancangan awal antara lain: panjang total kapal (Loa), panjang geladak (Ldl), panjang garis air ( $(\mathrm{Lw})$, lebar maksimum (Bmax), lebar garis air (Bwl), tinggi geladak $(\mathrm{H})$, sarat air (d), mesin penggerak (BHP), kecepatan kapal (VS), dan anak buah kapal (ABK).

\section{2) Desain Kapal Menggunakan Software Maxsurf}

Menurut Baeda (2002) Maxsurf adalah salah satu program aplikasi struktur yang dikembangkan oleh sebuah perusahaan pembuat perangkat lunak yang berlokasi di Fremtle Australia, yang bernama Formation System (FORMSYS). Sejak mulai diciptakan pada tahun 1984 sampai sekarang, Maxsurf telah mengalami banyak pembaruan terutama dalam hal perbaikan dan penyempurnaan metode-metode yang digunakan.

Sub-subprogram Maxsurf pada hakikatnya terdiri dari beberapa subprogram. Secara keseluruhan sub-subprogram tersebut antara lain:

a. Maxsurf Professional Sub, program ini pada hakikatnya bertujuan untuk membentuk lambung kapal yang akan didapat digunakan untuk menganalisis segala hal yang berkaitan dengan badan kapal.

b. Hydromax Proffesional Sub, program ini berupa aplikasi kapal dalam bidang analisis hidrostatistik, stabilitas, dan kekuatan kapal yang dapat langsung berintegrasi dengan Maxsurf. Hal ini memungkinkan penghematan waktu dalam pembuatan lambung kapal, yang kemudian dipergunakan sebagai acuan dalam proses analisis hidrostatistik, stabilitas, dan kekuatan kapal.

c. Hullspeed Sub, program aplikasi dari Maxsurf yang dipergunakan untuk menganalisis hambatan dan kekuatan suatu kapal untuk beberapa macam kondisi kecepatan.

d. Prefit Sub, program ini adalah perpaduan antara aplikasi data dengan offset dengan aplikasi penggambaran manual, di mana gambar yang dikerjakan dengan tangan disempurnakan dengan menggunakan data offset dari spreadsheet atau file teks lainnya.

e. Workshop Professional Sub, program ini diperuntukkan sebagai alat untuk membuat elemenelemen struktur kapal berdasarkan desain yang telah dikerjakan di software Maxsurf.

f. Span singkatan dari Sailing Performance Analysis yang merupakan salah satu subprogram yang bertujuan untuk memprediksikan kemampuan berlayar pada beberapa kondisi angin yang berbeda.

g. Hydrolink Sub, program yang didesain khusus untuk mentranslasikan data lambung kapal satu format ke format lainnya.

h. Fullplot Sub, program utilitas dari proses pencetakan dengan skala 1:1 untuk digunakan dalam lefting.

i. Digit Sub, program digitizer gambar lines plan atau general arrangement yang telah ada dan diperlukan untuk didesain ulang.

j. ACC Rule Sub, program utilitas pada perlombaan Yacht Americas Cup.

k. Seakeeper Sub, program integrasi dari analisis olah gerak kapal.

Maxsurf mempunyai kelebihan jika dibandingkan dengan beberapa program aplikasi lainnya, antara lain:

a. Mengacu pada proses desain manual yang telah bertahun-tahun digunakan, misalnya pada pembuatan titik kontrol yang berdasar atas posisi gading dan garis air.

b. Mengacu pada ketentuan-ketentuan dari organisasi keselamatan di dunia, misalnya IMO, MARPOL, US NAVY, dan lain-lain. 
c. Perkembangannya cepat dan mengacu pada kejadian-kejadian terbaru.

d. Tampilannya menarik dan sangat mudah untuk dipelajari, terutama untuk kalangan akademisi/universitas.

e. Keluaran dari analisis Maxsurf dapat dinampakkan pada hampir semua program aplikasi umum, seperti Ms. Office, AutoCad, Corel, dan lain-lain.

f. Hampir semua subprogram Maxsurf dapat saling berinteraksi secara bersamaan, sehingga proses pengujian dari analisis yang dilakukan dapat berlangsung secara efesien. Namun selain itu, terdapat pula beberapa kekurangan Maxsurf, antara lain: harga perpaket Maxsurf sangat mahal, sehingga jarang dipakai oleh pihak akademisi/universitas dan peralihan versi yang sangat cepat.

Pembuatan desain kapal dengan mempergunakan Maxsurf Pro mempunyai rentetan pekerjaan yang spesifik. Rentetan pekerjaan tersebut yaitu: penentuan dimensi kapal, penentuan bentuk dasar bagian-bagian kapal, penentuan dimensi bagian-bagian kapal, penentuan jumlah gading, penentuan jumlah garis air, penentuan jumlah buttock, penambahan control point, leveling dan bonding, grouping, locking dan rendering, pengecekan displacement, dimensi water line, koefisien bentuk, SAC, penyimpanan, dan pencetakan.

\section{3) Rancang Bangun (Basic Design)}

Rancang bangun (basic design) kapal penangkap ikan paling tidak terdiri dari tiga rancangan pokok yaitu: sketsa rancangan umum, rancangan garis air, dan rancangan konstruksi. Sketsa rancangan umum terdiri dari ruangan di bawah dan di atas geladak. Bagian bawah geladak dibagi oleh sekat melintang kedap menjadi beberapa ruangan (kompartemen) yaitu ruang ceruk haluan, ruangan/palkah ikan, ruangan mesin, ruangan tangki air tawar, ruangan ceruk buritan. Selain itu ada ruangan di atas geladak tata ruang yang terdiri dari rumah kemudi/tempat tidur nakhoda, ruang masuk kamar mesin, ruang akomodasi ABK, dapur, dan kamar mandi.

Rancangan garis air, menentukan karakteristik kapal di bawah garis air dan sebagai pola dasar untuk membangun kapal dengan melakukan proyeksi pada bidang melintang yang disebut body plan, pada bidang membujur disebut profile dan pada bidang horizontal disebut water plane pada skala 1:1. Dalam penentuan rencana garis air maka yang perlu diketahui yaitu penentuan koefisien-koefisien, ukuran pokok kapal, perkiraan displacement kapal, perkiraan kecepatan kapal, dan perkiraan displacement.

Adapun dalam rancangan konstruksi yang perlu diperhatikan yaitu jenis kayu yang digunakan. Menurut peraturan Biro Klasifikasi Indonesia (BKI) tahun 1996, jenis kayu yang digunakan konstruksi di bawah garis air adalah jenis kayu yang mempunyai berat jenis kayu (minimum) $700 \mathrm{~kg} / \mathrm{m}^{3}$ dengan kelembaman $15 \%$ dan untuk di atas garis air adalah jenis kayu yang mempunyai berat jenis minimum $560 \mathrm{~kg} / \mathrm{m}^{3}$ dengan kelembaman $15 \%$, serta untuk konstruksi lainnya adalah jenis kayu yang mempunyai berat jenis minimum $450 \mathrm{~kg} / \mathrm{m}^{3}$ dengan kelembaman $15 \%$. Selain itu, juga harus memerhatikan ukuran konstruksi/scantling berdasarkan peraturan BKI 1989.

Selain tiga hal di atas, juga harus diperhatikan beberapa aspek di dalamnya, meliputi: berat kapal, penetapan koefisien-koefisien, sketsa garis air, perhitungan tenaga mesin penggerak dan pemilihan mesin utama, serta perhitungan dan pemilihan tenaga generator set (genset). Dalam berat kapal tersebut yang perlu diperhatikan yaitu: berat kapal kosong, berat kapal pada kondisi keberangkatan (departure), berat kapal pada kondisi operasi (during fishing), berat kapal pada kondisi tiba di pelabuhan (arriving port), dan gross tonnage (GT). Pada penetapan koefisienkoefisien terdiri dari: penetapan koefisien balok (CB), koefisien prismatic (CP), koefisien midship (CM), serta penetapan koefisien kontrol $\mathrm{M}$ dari rasio antara panjang garis air terhadap akar pangkat, dan displacement. Selanjutnya ada beberapa hal yang perlu diperhatikan yaitu pengecekan volume dan displacement, serta pengecekan stabilitas. Perhitungan tenaga mesin penggerak dan pemilihan mesin utama harus benar-benar melakukan perhitungan tenaga mesin, mengetahui hubungan antara kecepatan dengan tenaga mesin, pemilihan tenaga mesin, serta pemilihan baling-baling. Terakhir, perhitungan dan pemilihan tenaga genset yang meliputi perhitungan electric power balance dan pemilihan genset. Dalam pemilihan genset yang perlu diperhatikan antara lain: spesifikasi genset utama dan cadangan, baik tipe mesin, daya mesin, dan putaran permenit/RPM). 
4) Spesifikasi Teknis Kapal Penangkap Ikan

Hal ini disajikan untuk menjelaskan rancang bangun kapal penangkap ikan yang terdiri dari:

a) Karakteristik

Pada umumnya rencana kapal penangkap ikan mempunyai karakter yaitu: (1) Konstruksi kapal mempunyai lambung, geladak, dan bangunan atas terbuat dari kayu. (2) Kapal dilengkapi 1 unit propulsi dengan system conventional shaft yang mempunyai kesanggupan maneuver yang baik. (3) Kamar mesin dilengkapi sistem sirkulasi udara (ventilasi) yang baik. (4) Kapal mampu membawa ABK kurang lebih 20 orang. (5) Bentuk dasar lambung harus mengikuti kriteria parameter yang diisyaratkan oleh FAO sehingga mempunyai stabilitas dan kinerja yang baik.

b) Spesifikasi

Dalam spesifikasi yang perlu diketahui antara lain: (1) Ukuran utama kapal, untuk ukuran utama kapal meliputi: panjang keseluruhan, panjang geladak, panjang garis air, lebar maksimum, lebar garis air, tinggi geladak, sarat tengah kapal, mesin penggerak, kecepatan kapal, trip peroperasi, jarak jelajah, dan ABK. (2) Kapasitas kapal, untuk kapasitas kapal meliputi: bahan bakar, air tawar, palkah ikan (ikan dan es), dan GT. (3) Propulsi kapal, untuk propulsi kapal meliputi: jumlah mesin utama, output mesin (BHP), putaran maksimum, dan fixed propeller. (4) Kecepatan dan jarak jelajah. (5) Bentuk kapal. (6) Trim dan stability.

c) Tata Ruang

Hal yang perlu diperhatikan dalam tata ruang antara lain: (1) Dalam lambung, sekat kedap air sebanyak enam buah melintang membagi lambung kapal menjadi lima buah ruangan (compartment) antara lain: ruang ceruk buritan, ruang tangki air tawar, ruang mesin, palkah ikan, dan ruang ceruk haluan. (2) Di atas geladak kapal antara lain: rumah kemudi/kamar tidur nakhoda, ruang akomodasi ABK, kamar mandi, dan dapur. (3) Awak kapal tergantung kapasitas maksimal kapal tersebut.

d) Konstruksi lambung

Kontruksi lambung yang perlu diperhatikan antara lain: (1) Material (insulasi palkah ikan, terbuat dari bahan polyurethane foam dan scantling, kontruksi kapal ditentukan oleh besaran modulus dan momen inersia dari balok kayu berdasarkan peraturan yang diisyaratkan oleh BKI. (2) Tangki-tangki (tangki air tawar, tangki bahan bakar, dan tangki minyak pelumas). (3) Pondasi mesin, konstruksi balok pondasi mesin dipasang sepanjang kamar mesin, diikat dengan penegar sekat kamar mesin secara sempurna dan melintang, diperkuat dengan gading besar, serta plat pengikat bracket pondasi sehingga menjadi satu kesatuan unit konstruksi terpadu. (4) Palkah ikan, untuk pemeliharaan suhu di dalam palkah menggunakan sistem pendingin es, maka sekeliling palkah ikan dipasang insulasi polyethurane foam.

e) Peralatan geladak, akomodasi, dan perlengkapan lainnya.

Hal yang harus diperhatikan dalam peralatan geladak antara lain: mesin geladak, kemudi, tiang tambat, pisang-pisang (fender), serta tiang bendera, dan pagar (railing) sedangkan untuk pelaratan akomodasi, meliputi: pintu, jendela, lubang palkah (hatch coaming), lubang orang, dan ventilasi. Perlengkapan terdiri dari: perlengkapan tambat sauh, perlengkapan keselamatan, perlengkapan pemadam kebakaran, perlengkapan akomodasi, kamar mandi, perlengkapan dapur, perlengkapan navigasi, perlengkapan komunikasi, perlengkapan alat penangkap ikan dan alat bantu, inventaris navigasi, dan inventaris kamar mesin.

f) Permesinan, perpipaan, dan instalasi listrik

Pada umumnya permesinan, perlengkapan, dan peralatan dirancang agar mempunyai kemampuan/tenaga yang cukup pada saat kapal beroperasi atau pada kondisi sebagai berikut: suhu ambeyent dalam kamar mesin maksimum $40^{\circ} \mathrm{C}$, kelembaban relatif di kamar mesin $90 \%$, suhu air laut $32^{\circ} \mathrm{C}$, dan suhu di luar ruangan $38^{\circ} \mathrm{C}$. Selain itu, harus memerhatikan: spesifikasi dari mesin utama, poros baling-baling, baling-baling, pompa geladak, pompa dinas umum, pompa pemadam kebakaran, bilga, pompa air, dan pompa transfer bahan. Selanjutnya, semua pipa-pipa harus mempunyai diameter yang sesuai dengan fungsi pompa. Adapun yang perlu diperhatikan untuk pipa-pipa tersebut antara lain: sistem bahan bakar, bilga, dan gas buang 
sedangkan dalam instalasi listrik harus memerhatikan jaringan listrik, papan hubung, dan lampu-lampu.

5) Aspek Ekonomi dalam Pembangunan Kapal Penangkap Ikan

Berdasarkan rancang bangun kapal perikanan dan spesifikasi teknis, maka estimasi biaya pembangunan/pembuatan kapal penangkap ikan dengan konstruksi kayu antara lain:

a. Konstruksi dan perlengkapan kapal didapatkan dari hasil perkalian $80 \%$ dari jumlah biaya produksi. Adapun bagian-bagian konstruksi dan perlengkapan kapal: struktur lambung (hull structure), bangunan atas, pekerjaan penyambungan, peralatan lambung, peralatan geladak dan akomodasi, tiang penyangga alat tangkap, sistem dalam kapal, permesinan, perlistrikan, perlengkapan dalam kapal, bilga, dan pengecetan.

b. Jumlah upah kerja didapatkan dari hasil perkalian $15 \%$ dari jumlah biaya produksi.

c. Overhead produksi didapatkan dari hasil perkalian $5 \%$ dari jumlah produksi.

d. Jumlah biaya produksi didapatkan dari hasil pembagian konstruksi dan perlengkapan kapal dengan 0,8 .

e. Overhead umum didapatkan dari hasil perkalian $8 \%$ dari jumlah biaya produksi.

f. Jumlah biaya umum didapatkan dari hasil penjumlahan jumlah biaya produksi dengan overhead umum.

g. Keuntungan pembangunan didapatkan dari hasil perkalian 10\% dari jumlah biaya umum.

h. Jumlah biaya keseluruhan didapatkan dari hasil penjumlahan antara jumlah biaya umum dengan keuntungan pembangunan.

i. Pajak Pertambahan Nilai (PPN) + Pajak Penghasilan (PPh) didapatkan dari hasil perkalian $11,5 \%$ dari jumlah biaya keseluruhan.

j. Harga jual/beli kapal didapatkan dari hasil penjumlahan antara jumlah biaya keseluruhan dengan PPN + PPh.

k. Biaya perizinan, surat-surat kapal, dan biaya penyeberangan.

I. Biaya alat penangkap ikan.

6) Aspek Finansial Kapal Penangkap Ikan

Terkait pembahasan aspek fiansial (keuangan) akan diuraikan mengenai gambaran keadaan keuangan usaha perikanan tangkap sebagai pertimbangan untuk merealisasikan pembangunan kapal penangkap ikan ini. Dikemukakan pula anggaran biaya investasi dan pengeluarannya, proyeksi pendapatan dan pengeluaran, proyeksi aliran dana, serta penerapan beberapa metode evaluasi finansial. Proyeksi dan analisis keuangan menunjukkan besarnya investasi dan kemampuan usaha untuk menghasilkan uang serta kemampuan membayar semua pinjaman selama lima tahun proyeksi. Adapun yang perlu diperhatikan dalam aspek finansial ini antara lain: kebutuhan dan sumber dana, analisis hasil usaha, analisis arus kas, analisis kelayakan proyek investasi, di mana dalam analisis tersebut yang perlu diperhatikan analisis nilai tunai bersih sekarang (Net Present Value), Net B/C Ratio, Internal Rate Return, serta Payback period.

\section{SIMPULAN}

Berdasarkan studi kasus yang telah dilaksanakan dalam metode perancangan kapal penangkap ikan, tahapannya antara lain: metode kapal pembanding, metode statistik, metode iterasi, dan method of complex solution sedangkan dalam tahapan perancangan kapal penangkap ikan meliputi perancangan aspek teknis, estimasi biaya pembangunan kapal, serta perancangan aspek finansial operasional kapal.

\section{DAFTAR PUSTAKA}

Baeda. (2002). Tutorial Komputer Teknik Perkapalan. Makassar (ID): Master Pro.

[BKI] Biro Klasifikasi Indonesia. 1996. Buku Peraturan Klasifikasi dan Konstruksi Kapal Laut. Jakarta.

Djaelani AR. (2013). Teknik Pengumpulan Data dalam Penelitian Kualitatif. Semarang (ID): FPTK IKIP Veteran Semarang. 
Palgunadi. (2007). Desain Produk 1: Desain, Disainer, dan Proyek Desain. Bandung (ID): Institut Teknologi Bandung.

PT. Tulada Konsula. (2005). Laporan Akhir Penyusunan Basic Design Rancang Bangun Kapal Perikanan. Jakarta (ID): Departemen Kelautan dan Perikanan.

Ronald MH, Syarifuddin, Zain J. (2014). Buku Ajar Rancang Bangun Kapal Perikanan. Pekanbaru (ID): Fakultas Perikanan dan IImu Kelautan, Universitas Riau.

[SNI] Standar Nasional Indonesia. SNI 01-7277.2-2008. Istilah dan Definisi-bagian 2: Kapal Perikanan. Jakarta (ID): Badan Standarisasi Nasional.

Unus F. (2004). Analisis kebijakan mengenai keselamatan nelayan dan kapal ikan di laut. Skripsi. Departemen Pemanfaatan Sumberdaya Perairan Fakultas Perikanan dan IImu Kelautan. Institut Pertanian Bogor. 